\title{
La Constitución de Weimar en los desafios del siglo XXI. Una mirada desde Latinoamérica
}

\author{
Jackson R. Valbuena Cure \\ Universidad Sergio Arboleda \\ jacksonrenevalbuena@hotmail.com
}

I.

La Constitución de Weimar en los desafios del siglo XXI. Una mirada desde Latinoamérica es el resultado investigativo en que convergen factores académicos, culturales y políticos. En primer lugar, el libro es consecuencia del workshop, títulado del mismo modo, llevado a cabo entre el 16 y 20 de septiembre de 2019 en la ciudad de Weimar (Alemania), y desarrollado en el contexto de la conmemoración del primer centenario de esta Carta Política. En este escenario, se discutió sobre los desafíos que enfrenta el legado de dicha Constitución en los ámbitos de la globalización, la multiculturalidad, las diferencias religiosas, las migraciones y los problemas ambientales. Se trató de un ejercicio de comprensión intercultural y crítico sobre los desarrollos de la Constitución de Weimar, además, con un especial énfasis en lo que deja dicha Constitución respecto a una comprensión limitativa del poder político a partir de los derechos consagrados constitucionalmente. En esa medida, en segundo lugar, puede decirse que el texto es el producto de un escenario de crítica y debate sobre los diversos rezagos contemporáneos en materia de protección a los derechos 
fundamentales y sociales. En tercer lugar, el texto puede ser visto, también, como un libro en el que se encuentran autores provenientes de todas las regiones de Latinoamérica, en los cuales coincide un compromiso ciudadano, académico y político con la defensa de las libertades y los derechos fundamentales de los ciudadanos. Se trata, en esta medida, de la confluencia de distintos procesos investigativos y de reflexión acerca de la evolución del Constitucionalismo social y la defensa de múltiples límites al poder punitivo.

La conmemoración del primer centenario de la Constitución de Weimar sirve para reflexionar sobre un hito histórico-jurídico en materia de consagración y defensa de derechos fundamentales y garantías constitucionales. Los distintos aspectos regulados en esta Constitución fundan parámetros, en términos de garantías y derechos fundamentales, que se expandieron rápidamente por toda Europa e incluso, también, por América Latina. Los aportes de dicha Carta Política trascendieron al mundo del derecho a tal punto que podría afirmarse que marca un antes y un después en materia de defensa de derechos fundamentales y sociales.

El libro expresa con fidelidad el entusiasmo que despertó la Constitución de Weimar al respecto y, en sus diversos capítulos, discute la vigencia de los hechos acontecidos ya hace cien años y que aún son objeto de discusión. La aplicación de los logros de la Constitución Weimar en un mundo globalizado, multicultural, influenciado por las nuevas tecnologías y envuelto en una realidad muy distinta a la de 1919 es un gran reto. Este desafío es aún más grande si dicha comprensión se traslada a un continente como el Latinoamericano, cuyo contexto social, económico y político es bastante distinto al europeo. Es por ello que el libro concreta un logro destacable, como lo es el aterrizar esta compleja discusión frente a algunas de las difíciles problemáticas contemporáneas que vive Latinoamérica. Este aporte es de realzar no solo respecto al libro, sino, también, del workshop en que se enmarca, precisamente porque permite visibilizar y discutir con profunda sinceridad los múltiples problemas continentales que se podrían entender como resultado de la deficiente aplicación de los principios heredados desde la Constitución de Weimar. 
El primer capítulo del texto es escrito por Marlus H. Arns de Oliveira (Brasil) titulado $O$ novo constitucionalismo latinoamericano como forma de arrefecer $o$ aparente paradoxo entre constitucionalismo e democracia. El artículo enmarca los procesos libertadores iniciados en la década de 1980 como palanca que impulsa las democracias constitucionales en Latinoamérica, que dan paso al nuevo constitucionalismo y permiten la recepción de los fundamentos sociales de la Carta política de Weimar.

Christian Scheechler Corona (Chile) aportó el segundo trabajo del libro titulado ¿Es la dignidad humana el bien jurídico en el delito de tráfico de migrantes? Aproximaciones desde la legislación chilena. La teoría del bien jurídico se ha convertido en un eje central del Derecho Penal actual, puesto que es una herramienta protectora de los límites al ius puniendi. La aproximación a la legislación chilena aterriza una problemática cuya solución puede estar en un clásico principio establecido en el "Catálogo de Derechos de Weimar" como lo es la dignidad humana, probando que los aportes de ésta son capaces de resolver problemas actuales en el contexto latinoamericano.

Marvin Alfredo Gómez Ruiz y Lizbeth Xóchitl Padilla Sanabria (México) contribuyen con el tercer capítulo intitulado La constitución alemana de Weimar 1919: apuntes desde la experiencia doctrinal y jurisprudencial mexicana. En este texto se trata el tópico de los principios tributarios constitucionales, para cuya conformación y evolución la Constitución de Weimar prestó un servicio de gran consideración. Aplicados a la realidad mexicana, el artículo discute la importancia de comprenderlos como derechos humanos con miras a asegurar la eficacia del perfil social de la Constitución.

México y la traición a la Constitución social de 1917, es el texto que escribe Rodolfo González Espinosa (México), con el que se compone el cuarto capítulo del libro. El abuso de figuras punitivas como la prisión preventiva y la mayor punición de los delitos en México, han logrado corroer los avances en el campo de derechos sociales, muchos de ellos consagrados en la Constitución mexicana de 1917 de forma previa a Weimar. Con este estudio se trae a colación no 
solo la crisis constitucional que atañe a México, sino, además, a gran parte de Latinoamérica en lo que respecta al abuso de diferentes figuras como la prisión preventiva, el arraigo y el aumento en las penas.

Jesús Omar Herrera Torres (México) anexa su trabajo en el quinto capítulo titulado La importancia del constitucionalismo social en el siglo XXI en materia político criminal en México. Los derechos sociales parecen ser parte central de las Constituciones actuales, sin embargo, su aplicación en la política criminal es difusa, sobre todo en Latinoamérica. Con el texto se hace una pertinente denuncia de las tácticas penales utilizadas en contra un derecho penal respetuoso de las garantías que ya en el nuevo constitucionalismo se consagraban a favor de los perseguidos penalmente.

El texto Un siglo entre dos constituciones. Consideraciones de método e historia constitucional sobre un modelo penal en común, escrito por Leandro Eduardo Astrain Bañuelos (México), es el sexto capítulo del libro. En esta lectura se narra una historia de precedentes que fundamentan las primeras constituciones que consagran derechos sociales, es decir, la Constitución de México de 1917 y la de Weimar de 1919. El trabajo destaca la importancia de los programas penales de ambas cartas fundamentales, tributarios del Derecho penal liberal pero adicionados de componentes derivados del constitucionalismo social, que fortalecieron la esencia garantista del Derecho penal propio de un Estado social y democrático de Derecho.

Miguel Lamadrid Luengas (Colombia) ubica los logros de la Constitución centenaria como un referente para Latinoamérica en su texto Lecciones de la Constitución de Weimar para Colombia. El artículo narra el papel proteccionista frente a los derechos fundamentales que tienen las Constituciones que consagran derechos sociales. El trabajo resalta enfáticamente la importancia de la revisión judicial de mano de una jurisdicción constitucional como un elemento preponderante para los sistemas jurídicos actuales. En el campo del derecho penal, esa protección y preservación de los derechos fundamentales resulta una garantía esencial en países como Colombia contra los abusos del poder.

Cristina E. Montalvo y Rafael E. Nieto (Colombia) contribuyen con el octavo capítulo titulado Importancia del constitucionalismo social para la política victimal en Colombia ¿un asunto de politica criminal? En el mismo se explora la 
importancia del constitucionalismo social en la creación y génesis de la política criminal centrada en las victimas. El texto enseña una especial sensibilidad respecto a la afectación de derechos que han tenido lugar en el marco del conflicto armado en Colombia, con el que se ha generado un escenario de dificultad para la protección de las víctimas.

El noveno capítulo denominado Repercusiones de la Constitución de Weimar en la Constitución de la República bolivariana de Venezuela y la política criminal actual es un aporte al compilado de este centenario desarrollado por Laura María Bastidas Zambrano (Venezuela). La situación actual en Venezuela es deplorable, no permite el ejercicio pleno de las garantías fundamentales y derechos. En el texto se critica la situación actual de este país y se compacta una advertencia para toda Latinoamérica sobre la necesidad de proteger los derechos fundamentales.

Mario Orlando Contreras (Argentina) traslada el debate hasta Argentina con su texto La constelación del federalismo argentino, influenciado por la Constitución de Weimar. Este trabajo delimita el décimo capítulo del libro y permite un recorrido histórico y geográfico por Argentina, distinguiendo los momentos y lugares claves en los cuales la filosofía nacida con la Constitución de Weimar llegó a expandirse por Argentina, aporte que permite entender la influencia de esta en un contexto distinto al europeo.

El Estado Social como herencia de la Constitución de Weimar a 100 años de su promulgación es un trabajo anexado por Silvia Patricia López González (México) en el undécimo capítulo. Hay aportes innegables al constitucionalismo moderno que son celebrados en esta conmemoración, tanto en el ámbito de los Derechos fundamentales como de los Derechos económicos, sociales y culturales. Sin embargo, el aporte más interesante radica en la consolidación de estos derechos en una realidad denominada Estado Social. Con esto se da un sentido de bienestar social con base en los derechos sociales y se otorga un reconocimiento explícito y trascendental a la dignidad del ciudadano.

Al final y a manera de síntesis, John Zuluaga (Colombia) aporta su artículo $L a$ Constitución de Weimar: rupturas y desafios. En este texto se exaltan los logros alcanzados con la promulgación de la Constitución, se enlaza al contexto de la política criminal y se concluye estableciendo los retos que representa aplicar dichas garantías en el siglo XXI y en América Latina. 
Los ricos aportes de este libro delimitan un panorama de cuestionamientos sobre la realidad latinoamericana. La conmemoración del centenario de la Constitución de Weimar revitaliza el permanente llamado a repensar nuestra relación con múltiples garantías constitucionales $\mathrm{y}$, especialmente, a inmiscuirnos en la defensa de los límites constitucionales del poder político. Esta publicación, además, representa un hito histórico pues abre las puertas a todos los científicos latinoamericanos en el campo de las ciencias jurídicas para continuar con la visibilización de sus aportes académicos en Europa por medio de la serie de publicaciones en lengua castellana inaugurada por Eckhaus Verlag en Alemania. De esta manera, se refuerza el proceso de intercambio académico y cultural con los países germanoparlantes, permitiendo que las diversas y ricas reflexiones jurídicas que se llevan a cabo en Latinoamérica puedan ser conocidas, también, en estos países.

\section{Bibliografía}

Libro: La constitución de Weimar en los desafíos del siglo XXI. Una Mirada desde Latinoamerica.

Autores: varios

Lugar: Weimar, Alemania.

Año: 2019.

Coordinadores: Kossel, M; Zuluaga, J.

Editorial: Eckhaus Verlag.

Cómo citar el artículo: Valbuena J.R. (2020). La Constitución de Weimar en los desafíos del siglo XXI. Una mirada desde Latinoamérica. Derecho Global. Estudios sobre Derecho y Justicia, 5 (13), pp. 161-166. 